\title{
A Case Study of Employee Participation in a Workplace ESL Program
}

\section{Antonella Valeo}

This article reports the findings of a study undertaken in the spring of 1997 of a workplace ESL program offered at a rubber parts manufacturing plant in Toronto. The purpose of the study was to recommend changes in program delivery that might facilitate and encourage employees to enroll in the ESL program. The premise of the study was the belief that given appropriate circumstances and conditions, all employees can be motivated to participate. This premise was supported by similar research in the field that explored how various factors beyond the desire to learn may affect an individual's decision to participate in formal learning opportunities. In order to explore these factors, a questionnaire was distributed to employees. Based on the findings from this survey, the following recommendations were made. First, classes should be held during the working day and that part of the class time be paid for. This was to replace the cash incentive provided by the employer at the end of the program year. Second, the location of the lessons should be moved from the existing location, the cafeteria, to a meeting room. Last, the program should be strengthened by greater involvement of employees and employer in program development.

\section{Introduction}

Canada has a long tradition of welcoming new immigrants from all over the world. They have brought with them a variety of skills that benefit the Canadian workforce greatly. Increasingly, however, workplace demands have focused on specific skills, in particular, communication skills. The production workplace has seen some of the greatest changes. Greater emphasis on team work and integrated responsibilities, an increased reliance on complex technology, and a move toward uniformity in production standards across industry have created demands for a higher level of communication skills on the part of employees (Rubenson \& Schutze, 1995). In response to this demand, programs offering English as a second language with a focus on workplace communication have proliferated. Most often enrollment and attendance are voluntary, so program developers must decide how to best promote employee participation. In order to explore employee decisions to participate or not, a study was undertaken in the spring of 1997 of a workplace ESL class offered at a rubber parts manufacturing plant in Toronto. In this study, participation was primarily defined as enrollment in the program. The goal of the study was to examine factors affecting employee 
participation and to recommend program changes that would increase enrollment.

\section{The Role of Motivation in Participation}

Employee participation in voluntary workplace programs is often associated with individual motivation. It is often assumed that some people want to learn and others simply do not. This perspective, however, may be misleading and inappropriate to the situation explored in this study. Rockhill (1983) warns of "the risks to approaching participation as a problem in motivation. One is that it reifies motivation at the expense of situational factors that also bear a heavy influence upon the event of participation" (p. 23). This reference to situational factors or context can be seen throughout the literature on motivation and participation. Rogers (1996) states that the "learning situation" provides a context for motivation. Cross (1981) distinguishes between situational, institutional, and dispositional factors that affect participation. In workplace education and training, Puchner (1995) found that "the individual condition of 'being motivated' depends most on the contextual conditions surrounding the individual" (p. 163). Contextual factors may be assessed by examining the environment in which the individual lives and works. They may also be examined by asking the employees themselves reasons for their decisions.

In exploring the motivation of participants, Houle (1963) provided a profile of the various types of learners found in adult learning situations. He interviewed participating adults and identified three learner types: goaloriented learners, activity-oriented learners, and learning-oriented learners. The goal-oriented learner looks for tangible reward such as opportunity for promotion at work. The activity-oriented learner enjoys the act of participation and is thus satisfied with the rewards of social contact. The learningoriented learner participates in adult education for the sake of learning something new. Although Houle's work did not focus on identifying incentives to increase participation, the focus on learner types helps dispel the notion that all participants are motivated in the same way, that they are naturally "learners" in a way that others are not. Furthermore, Houle found that these types were not discrete, as learners gave multiple reasons for participating and, therefore, represented shades of these broader categories of learner types.

Houle's (1963) conclusions were echoed in the research of Tough (1968), who explored what he termed "conscious motivation," the impetus behind the choice to begin and continue a learning project. Like Houle's research, Tough's work was based on interviews of participating adults. These interviews showed that, once again, the typical learner gave several reasons for participating in a learning project. This supports the suggestion that the 
decision to participate and, conversely, not to participate is complex, not easily summed up as an act of the motivated or unmotivated.

A second finding of Tough's (1968) study that is highly relevant to the focus of this project concerns the specific reasons for which people take action to engage in learning activities. Of 13 reasons suggested by the researchers to the interviewees, the reason most commonly given for participating was "use to take action," reflecting "the desire to use or apply the knowledge or skills" (p. 52). This finding was common to Houle's (1963) goal-oriented learner as an important motivator and can be seen in a number of studies including the work of Cross (1981) who concluded from her research that "most adults are not much interested in storing knowledge for later use or in locating answers to questions they do not have" (p. 90), but rather to use this knowledge immediately.

Research in motivation has also focused on answering the question of why some adults do not participate in educational opportunities, attempting to identify specific factors that influence participation. Cross (1981) identified three categories of influences: situational factors, institutional factors, and dispositional factors. Situational factors are aspects of the learner's personal life such as family responsibilities, which prevent or discourage participation. These are subject to change over time, yet often appear to be beyond the individual's control. Institutional factors such as when the class is held are part of the organization and structure of the educational activity and may make it difficult or impossible for some adults to attend. Finally, dispositional barriers are those attitudes and perceptions about oneself as a learner, for example, the belief that one is "too old to learn."

The approach taken in this study rejects the assumption that some people, in this case employees, are motivated people who will always participate in learning opportunities whereas others are unmotivated by nature and will always chose not to participate. The research is based on the premise that motivation is individual, changeable, and contextual.

\section{The Study}

The purpose of the study was to discover factors that may influence employee participation in the ESL program in order to be able to recommend changes in program delivery that might facilitate participation. The study focused on a group of 145 employees employed in a nonunionized rubber parts manufacturing plant in Toronto. They were employed as machine operators, mechanics, electricians, lead hands, and drivers, all on day shift across five departments in the plant. Each department was managed by either one manager or a team of two managers for the larger departments, with a total of seven managers in all. The managers reported to the vicepresident of the production division operating at the plant. 
For the most part, work consisted of producing pieces from raw material or assembling parts. Shop floor workers commonly worked either alone or with one other worker. Their work time was recorded with a punch clock, and they were expected to meet production quotas in a work day. Among the shop floor employees oral communication consisted of brief, simple exchanges such as asking for more raw material or reporting equipment failure. Their work also required that they maintain production records by checking off items on lists and writing in amounts. Communication between the employees and their managers ordinarily involved brief instructions and clarification of information or problems such as supplies shortages or personal leave. This communication was ordinarily carried out in English, and occasionally in other languages between bilingual managers and employees. Employees also attended monthly departmental meetings, which were held for the most part in English with translation by bilingual managers or other employees as needed. Occasionally employees attended larger gatherings involving executive staff, which were held in English with simultaneous translation provided at the time. Employees took regularly scheduled breaks, which were spent in the cafeterias usually talking in their first language with other employees.

The ratio of men to women in the sample group was fairly equal; however, this varied considerably by department, with some departments being predominantly or exclusively male and others female. The native language spoken by over $60 \%$ of this group was Portuguese, followed by Chinese, then Greek, Turkish, Kurdish, Tagalog, Hindi, Tamil, Punjabi, and Italian. Most of the group had been in Canada 10 years or more, and although the language levels varied, most had a fairly basic command of English. The managers varied widely in their time with the company and in their particular department. All were bilingual: four spoke Portuguese, two spoke Italian, and one spoke Chinese.

\section{The ESL Program}

At the time of this study the ESL program was in its fourth year of operation, implemented and administered as a partnership between the employer and the school board. The employer supplied a location in the plant, which was at the time the cafeteria. The production division administrative assistant volunteered to act as liaison between the employer and the board. In addition, the employer provided $\$ 10$ a week for all employees attending regularly, light refreshments in class, and a gift commemorating their participation in the course. The school board provided an instructor and support material. A certificate of completion was also awarded on behalf of the school board and the employer to each participant at an annual graduation ceremony. Of 145 employees eligible to participate in the program, 29 day shift employees and 10 evening shift employees were enrolled. The third, night shift did not 
participate. Only the day shift employees were studied in this research so as to limit the variability of contextual influences. Classes were held twice a week for two-hour periods following their work shift, from 4:00 p.m. to 6:00 p.m. The program ran from October to May.

\section{Research Methodology}

Information was gathered primarily from a questionnaire distributed to employees. One questionnaire was distributed to those employees who participated (Appendix A), and another was distributed to employees not participating in the ESL program at the time (Appendix B). All the material was in English only, simplified to accommodate the literacy levels of the employees. The questionnaires included questions asking the employees to identify specific reasons for enrolling or not enrolling in the program. Other questions asked for their opinions regarding specific aspects of the program. Another group of questions asked for information about themselves, including information about age, work, and family. Information was gathered to explore whether certain features of the program systemically limited employee participation. Of 145 questionnaires distributed 43 were returned from nonparticipating employees and 23 were completed by those employees enrolled in the program.

Also included in the study were interviews of the seven department managers, who were interviewed individually in order to assess the impact their attitudes toward the program and employee participation might have on their employees' decisions. This information was used primarily to lend support to any conclusions that might be drawn from the questionnaire.

\section{Limitations of the Study}

Before examining the results of the research, it is important to consider those factors that may have affected its validity and that may pose problems in interpretation and application. These problems arise primarily as a result of the questionnaire method used in the study. First, the content of the questionnaires, as is the nature of this method of research, was based on preconceived notions as to what factors might affect participation. The multiple-choice format reflected the specific concerns of the researcher and affected the responses given by the employees. In addition, this format, with formulated responses, could obscure the interpretation of the responses. For example, the response of "no time" to the question of why an employee did not attend could mean "more important things to do" or "busy during class hours," suggesting different obstacles to participation.

Another factor to be considered is the language of the questionnaires. One of the initial challenges was the low level of English literacy of a large number of the employees, making even the most simply worded questionnaire a difficult response task. This may be partly responsible for the lower 
than hoped for response rate as some employees may have found the questionnaire too difficult. Moreover, many of the respondents were employees with higher levels of English language skills. Therefore, those who in fact would benefit the most from the program offered were among those who participated the least in responding to the questionnaires and as such were more poorly represented in the study.

The method of distribution of the questionnaire may also have affected the response rate, and the quality of the responses. The nature of a time-sensitive production-based workplace discouraged the administration of the questionnaire during working hours to the employees not enrolled in the program. The employees were asked to take the questionnaire away and return it within a week. The questionnaires distributed to participants in the ESL program presented a different problem that, ironically, arose from the fact that they were not asked to take them away, but rather to complete them in class. As the questionnaires were being completed, discussion arose; it was evident that some respondents were being influenced by the more vocal members of the group. Although it does not necessarily invalidate someone's opinion simply because the person changed it on hearing a more convincing argument, it is prudent to keep this in mind when noting the high degree of uniformity in some of the responses.

Thus armed with caution and aware of the potential for misinterpretation, the results of these questionnaires may be examined and discussed.

\section{Results and Discussion}

In responding to the questionnaire, employees indicated a number of factors that seemed to affect participation adversely. In responding to the question "Why don't you come to English class?" nonparticipants most commonly chose "no time" as the answer. This response is open to a number of interpretations. It may be that ESL class is simply not a priority in relation to other responsibilities. It may also be that the time the class is held, from 4:00 p.m. to 6:00 p.m., after their shift is an inconvenient time for study when other responsibilities are more pressing. The latter suggestion is supported by the second most commonly chosen reason: "too tired." This issue was addressed further when employees were asked when they thought would a good time to study. "After work" was chosen by $33 \%$ of the respondents; however, $30 \%$ chose "lunchtime" as the best time. These findings suggest that the program schedule may be discouraging participation for many, and that holding the class during the working day may increase participation.

The question addressing the monetary incentive also proved informative. Although $75 \%$ of the nonparticipating respondents responded that it was important, over $80 \%$ expressed a preference for one hour of paid class time over monetary reward for attendance. A variety of studies confirm that money can be an important incentive (Puchner, 1995). However, a number of 
the employers in those studies provided this incentive in the form of potential for economic improvement: applying the skills learned led to the possibility of promotion. The money is thus linked to learning. In this ESL program, the monetary incentive is linked only to attendance. In addition to failing to address long-term educational and workplace goals, there appears to be some ambiguity in the employees' opinion of the incentive. Although over $75 \%$ of participants also described the incentive as very important, only $26 \%$ chose it as a reason for participating. Participants informally complained that nonparticipants often accused them of participating in the program only for the money. This conflict might be alleviated by offering employees paid time instead of money as an incentive.

In addition to information about the monetary incentive, the question addressing the importance of certain program features supported the continued inclusion of a certificate of completion granted to the employees. The certificate was described as "very important" by $80 \%$ of the employees participating in the ESL program.

The question of class location also proved informative. When asked where they thought the class should be held, $70 \%$ of the respondents chose a meeting room as preferable to the cafeteria in which the classes were being held.

An attempt to discover what motivated those employees who did participate in the program revealed some surprising results. The most commonly chosen response to the question of why the employees chose to participate was "to learn something new." On the surface, this information does not appear to support research that suggests that adult learners are predominantly interested in tangible rewards (Cross, 1981). Rather, it may support previous work on learner types suggesting that some people are simply learning-oriented (Houle, 1963), interested in learning for its own sake. This requires further clarification. Do adults learn the new skills for their own sake or in hopes of applying them? Further research is needed.

The second and third most commonly chosen responses to the question of why employees enrolled in ESL class were "to help me use English outside of work" and "to help me with my job." It is interesting that employees did not respond that they were primarily motivated to participate by a need for English on their jobs. Workplace classes are often supported by the employer in the hope of benefiting the workplace, and therefore the company, with improved language skills on the part of employees. This particular workplace was concerned with the employees' abilities to take part in the implementing of international quality standards adopted by the company. Yet these findings suggest that employees did not perceive the same need. This raises the issue of employee perception versus employer perception of workplace training needs and the necessity of both participating in setting up training and educational opportunities. 
In the interviews a number of the managers expressed frustration with the situation. Although the managers wanted employees with better English skills, some employees did not feel they needed to improve their English for their work. This disparity was linked to a number of workplace features, one of which was the simplistic nature of the work. Oral communication often consisted of simple phrases asking for more supplies. As one manager expressed it, "They don't need English now because they already know their jobs." Another manager suggested that the bilingual skills of the managers were demotivating with regard to learning English. Nearly all the managers spoke one of the two languages spoken by most of the employees as a first language, either Portuguese or Chinese. One manager reported that some employees refused to speak to him in English, although they were able to do so, because they knew the manager could speak their native language. The availability of first language use and translation may appear to alleviate language conflict. However, the study of a language program delivered at a semiconductor manufacturer in the United States proved otherwise: increased productivity and quality of work were attributed to a reduction in the time used for translation (Mikulecky, 1995). Workplace features are difficult to identify, further indicating the need for employer and employees to participate more fully in setting up and developing the ESL program in their workplace.

In response to the question of how the class had been helpful, the most common response was "I use English outside of work better" followed by "I don't feel so shy to speak English" and "I do my job better" as third. These results support the inclusion of non-workplace content in ESL classes in the workplace, a topic that is sometimes debated in co-sponsored programs between employers with a work production agenda and the instructional organization with a student-centered agenda. This confirms the results of the study of the ESL program at several Levi Strauss plants in Canada: participants interviewed reported that a great deal of their satisfaction with the classes stemmed from having acquired knowledge and skills they were able to use outside the workplace (Burnaby, Harper, \& Pierce, 1990).

\section{Recommendations and Conclusion}

Based on the findings of the study, it was possible to offer specific recommendations for program change with the intention of increasing participation. Specifically, it was recommended that class be held during the work day with one hour of class time paid for by the employer. This payment was to replace the monetary reward currently given by the employer. In addition, it was suggested that the class location be moved from the cafeteria to a meeting room. Another recommendation was for greater participation on the part of employer and employees in developing and promoting the program. 
In addition to providing data for program change, the results also confirmed the suitability of certain program delivery features such as granting a certificate of completion and the inclusion of non-workplace material in the curriculum. The complexity encountered in interpreting the responses also suggests the need for in-depth study into the structure and environment of the workplace that may affect employee participation in workplace programs.

\section{The Author}

Antonella Valeo has taught ESL in a variety of workplaces in Canada and abroad. She is currently working with the Toronto District Catholic School Board teaching language skills in an employment preparation program for foreign-trained engineers at Skills for Change. She has a TEFL Certificate from the University of Toronto and is completing her MEd with the University of Sheffield, UK.

\section{References}

Burnaby, B., Harper, H., \& Pierce, B. (1990). Significant factors relating to ESL classes in 3 Levi Strauss plants: Final Report. Toronto, ON: OISE Press.

Cross, P. (1981). Adults as learners: Increasing participation and facilitating learning. San Francisco, CA: Jossey-Bass.

Houle, C.O. (1963). The inquiring mind. Madison, WI: University of Wisconsin Press.

Mikulecky, L. (1995). Workplace literacy programs: Organization and incentives. In D. Hirsch \& D.A. Wagner (Eds.), What makes workers learn: The role of incentives in workplace education and training (pp. 129-149). Cresskill, NJ: Hampton Press. @REF = Puchner, L. (1995). Incentives for adult learning in developing countries: Lessons and comparisons. In D. Hirsch \& D.A. Wagner (Eds.), What makes workers learn: The role of incentives in workplace education and training (pp. 161-179). Cresskill, NJ: Hampton Press.

Rogers, A. (1996). Teaching adults (2nd ed.). Milton Keynes, UK: Open University Press.

Rockhill, K. (1983). Motivation out of context: Research on participation in continuing education. MOBIUS, 3(1), $22-27$.

Rubenson, K., \& Schutze, H.G. (1995). Learning at and through the workplace: A review of participation and adult learning theory. In In D. Hirsch \& D.A. Wagner (Eds.), What makes workers learn: The role of incentives in workplace education and training (pp. 95-116). Cresskill, NJ: Hampton Press.

Tough, A. (1968). Why adults learn: A study of the major reasons for beginning and continuing a leaming project. Toronto, ON: OISE Press. 


\section{Appendix A: Questionnaire Distributed to Employees Enrolled in the ESL Program}

Circle the number of your answer to each question.

\section{What is your sex?}

$$
\text { 1. man 2. woman }
$$

What is your job?

1. operator

2. mechanic

3. driver

4. lead hand

How old are you?

1. $18-29$

2. 30-39

3. $40-49$

4. $50-65$

What languages do you speak other than English?

How many years have you taken this class?

Why did you join the English class? You can circle more than one answer.

1. to help me with my job

2. to help me use English outside of work

3. for fun

4. because I was curious

5. to learn something new

6. to spend time with my friends

7. because my manager wants me to

8. for the money

9. for the certificate

10. to help me get a promotion

11. other

How do you think taking this English class has helped you? You can circle more than one answer.

1. I do my job better

2. I use English outside of work better

3. I don't feel so shy to speak English

4. I made some extra money

5. I have made new friends

6. I like my job more

7. It hasn't helped me

8. other

Will you take English class again next year?
1. yes
2. maybe
3. no
Why not?

1. no time

2. too tired

3. didn't learn anything

4. didn't like it

5. people make fun of me

6. other

Why do you think other people don't take this class?
1. no time
2. too tired
3. they feel too old
4. they think they can't learn
5. they don't like to study
6. they're too shy
7. their friends don't go
8. people make fun of them
9. they have to go home to their family
10. they don't want to learn English
11. other 
How important are these things to you? Choose one answer.

\begin{tabular}{|c|c|c|}
\hline $\begin{array}{l}\text { 1. very important } \\
\text {-graduation }\end{array}$ & 2. important & 3. not important \\
\hline $\begin{array}{l}\text { 1. very important } \\
\text {-certificate }\end{array}$ & 2. important & 3. not important \\
\hline $\begin{array}{l}\text { 1. very important } \\
\text {-the presents (book and sweatshirt) }\end{array}$ & 2. important & 3. not important \\
\hline 1. very important & 2. important & 3. not important \\
\hline
\end{tabular}

How did you find out about this class?

1. Edna* told me

3. my friend told me
2. my manager told me

4. I read a notice

What do you think the company should do to get more people to join the class?

Do have any other comments?

\section{Thank you!}

* Administrative assistant, liaison between employer and instructor. 


\section{Appendix B: Questionnaire Distributed to Employees not Enrolled in the ESL Program}

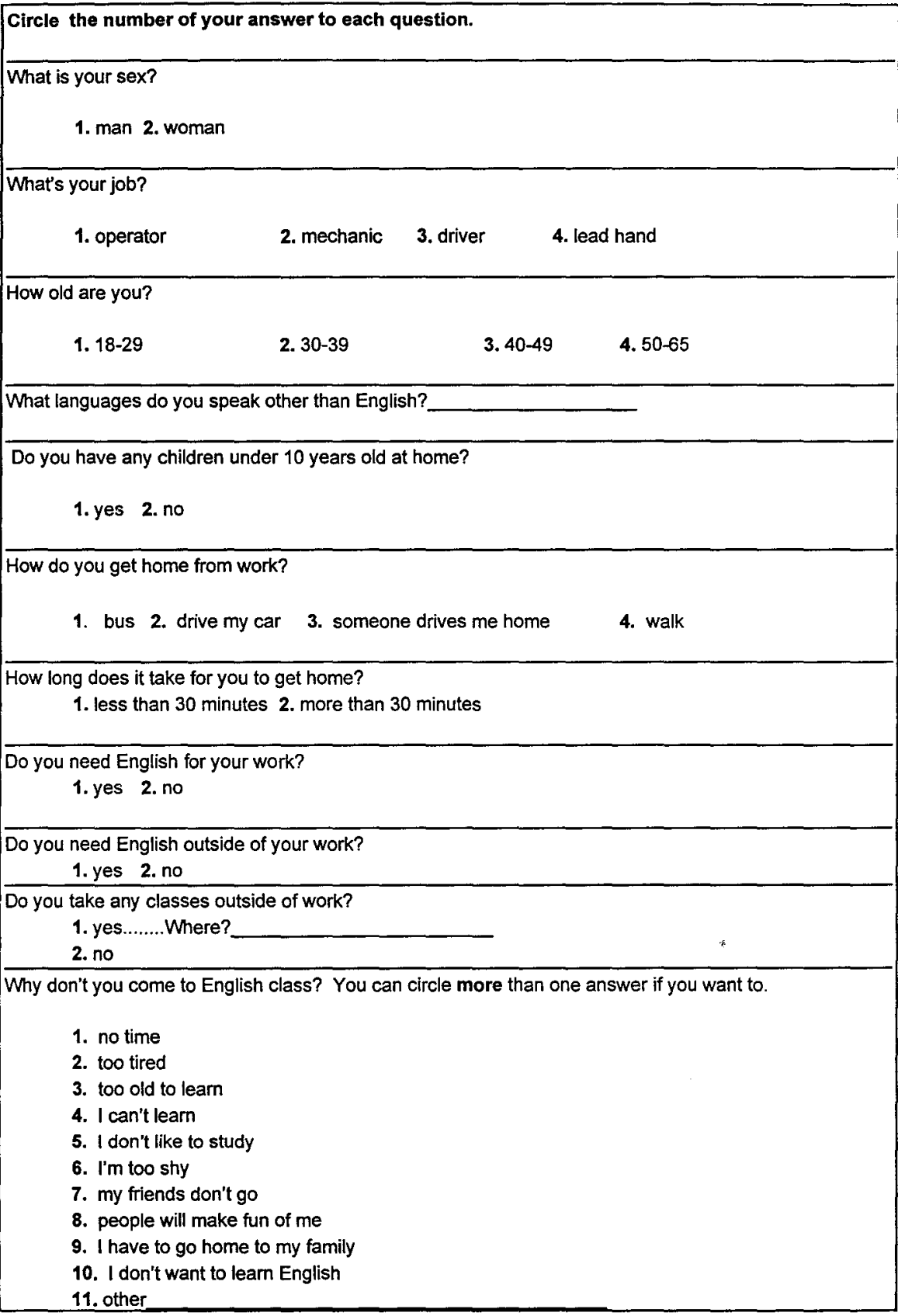


Why do you think other people don't come to English class? You can circle more than one answer if you want to.

1. no time

2. too tired

3. too old to learn

4. they can't learn

5. they don't like to study

6. they're too shy

7. their friends don't go

8. people will make fun of them

9. they have to go home to their family

10. they don't want to learn English

11. other

When is best to study?
1. before work
2. Iunchtime
3. after work
4. Saturday

How long is good to study?
1.3 months
2. 6 months
3.9 months

How many times a week is it good to study?
1. one time a week
2. two times a week
3. three times a week
4. more than 3 times a week

How important is the money the company pays every week?
1. very important
2. important
3. not important

Would you come to English class at lunchtime for a free lunch?
1. yes
2. no
3. maybe

What do you think is better for the company to give students?
1. money every week
2. one hour company paid time every class

Where do you think is a good place to study?
1. cafeteria
2. meeting room
3. other?

Do you want to say anything else about the English classes? 